\title{
Increased Materialistic Trends among Youth
}

\author{
Afsheen Masood \\ Institute of Applied Psychology, University of the Punjab, Lahore, Pakistan. \\ drafsheenmasoodmalik@gmail.com \\ Rubab Musarrat \\ University of Central Punjab, Lahore, Pakistan. \\ rubab_musarrat@hotmail.com \\ Shama Mazahir \\ Institute of Applied Psychology, University of the Punjab, Lahore, Pakistan.
}

\begin{abstract}
The goal of this qualitative research is to investigate the increased sense of materialism among youth. The main research question is to identify the factors which are causing materialism among youth. The sample of this research included 25 people, age group 18-25 years obtained from students that are enrolled in universities. The interpretive phenomenological approach was taken which was based on semi-structured interviews. The findings revealed that materialistic trends are increasing among youth nowadays. Because thought patterns of youth and societal demands have changed totally. Factors that are increasing materialism include social media, brand consciousness; self-centeredness; fake personality development and desire to be socially accepted. The implications indicate that materialistic trend should stop by controlling the social media possession among youth which is the primary source of enhancing materialism among youth.
\end{abstract}

Keywords: social media, parenting, brand consciousness, society, and lifestyle.

\section{INTRODUCTION}

A system that eats us from inside out is considered to be the preoccupation with material world which believes that success and progress are the highest value of life (Mombiot, 2013). Psychological study proves that materialism is creating a sense of conflict between rich and poor of the society. Materialist world means to study the economic and social life of man and the influence of materialistic things on person's thinking and feelings (Marx's, 1961). Two factors 
that enhance materialism were when people got any signal from friends, peers, parents and family members and the second factor comes when people feel insecure because of economic fears(Kasser, 2014). Parents and peers are the primary socializing agents which influence this lust among adolescents because they are the emotional and social support for a child and develop their self-esteem (Elsevier, 2010).

Materialistic trends among youth are increasing day by day, and according to one research the Americans shop twice than that of 55 years ago, and they have more luxuries and more money, but still there lust or craving for products is increasing rapidly (Gregoire, 2014). Consumer culture has influenced our societies, and it constructs the modern capitalism not only in the west but also in collectivist societies like Pakistan people are addicted towards this consumer culture (Alvi, 2014).

According to Zaheer (2012) Pakistani youth is spending their money just to be a part of society and focus more on materialistic things like cars, house and most importantly a wealthy life which gives them life satisfaction. Children use brand names as a perceptual care to identify things and develop a brand association with conceptual and symbolic meaning (John, 2003). Materialism is a complex phenomenon and those who associated their happiness with materialistic possession become stressed with the family structure (Robert, 2005). According to one research, Ka Wa Chan (2003) investigates that friends are the predictors of enhancing the endorsement of materialistic values and children go far away from family traditions. Products with local brand names are considered to be cheap as compared to national brand names which play a vital role in increasing self-consciousness (Bushman, 1993).

Possession plays an important role in creating a sense of self because it involves extended self which becomes a part of self because of possession and people wants to fulfill that possession (Belk, 2010). Ryan (2004) finds out from their research that people desires for material objects and society support increased their lust and they tried to accomplish their desires by consuming products because those eye-catching products that are available to us provoke us to purchase more and more. According to one research Barrett (1992) indicates that the undesirable consequences are related to high level of materialism such as loss of community sense within people. Different issues and criticism raised by people who are possessed to goods and 
materialism as it is associated with greed and jealousy (Belk, 1983).The impact of gaming on making healthy and unhealthy relationship within families and the aim of it is to know the needs of community members which show that they are based on materialistic things (Schalkwhyr, 2006).

According to Marmot (2001), it was examined that there is a relationship between life expectancy and average income which also depicts that mortality and income inequalities are highly interrelated to each other. Self-esteem is a very important psychological factor which may be problematic when a child enters his adolescence it was noticed that culture, social context, societal and interpersonal influences have a significant effect on personality (Rosenberg, 1989).According to Rindfleisch (1997), it was examined that young adults of isolated families are more materialistic and have a high level of consumption. This ratio of high compulsivity depends on family background and available resources, and socioeconomic status is also very prominent factor in enhancing stress. Self-concept is highly effected by brand consciousness child even have no concrete meanings in their mind but they following the path because they see others in that way (Chaplin, 2005). People often rely on social meanings, and they always wanted to fulfill social roles this research focuses that which products get more stimuli to behave (Solomon, 1983).Materialism is a stable trait, and there exists a relationship between materialism and susceptibility and how materialistic attitudes develop among children (Bachmann, 1997).

Those adolescents who are more informative about environmental changes are highly brand conscious because they perceived the greatest effects of product placements on others as compared to low brand-conscious teens (Nelson, 2005). Peer rejection is related to adolescent materialism and self-esteem, and it was suggested that peer rejection boosts adolescent materialism by lowering implicit self-esteem and that materialism is one way to compensate their implicit self-esteem ( Jiang, 2015). The purpose of research to look at the importance of social needs for social well-being and the healthy development of the youth. It was found out that social needs are connected to consumption behaviors such as branded clothes may be used to for satisfaction of one's social needs (Syrjala, 2015). To assess the possessions of materialistic values, it was explored that people with high in materialism seem to emphasize more utilitarian as well as appearance and status concerns (Richins,2004). 
Today, youth are more materialistic and less involved in hard work than the past. According to a study, in the past, the percentage of materialism among youth was 48 , and it has increased up to 62 percent of students (chee, 2013).It has become a belief that person who has more materialistic things has more satisfaction of life. A study suggests that there is an effect of neighborhood on developing materialistic values, saving and buying behavior among youth (taylor, 2012). According to a study, there is a relationship of materialistic youth and buying behavior. The materialistic youth respond to advertisement more than others. If parents are materialistic than there are more chances of developing materialism among their children (goldberg, 2003).

Research suggests that there is a role of environment in developing materialism among youth. Adolescents use branded things to develop self-concept among them. It was also explored that there is a difference of age developing brand connection with the self concept (Chaplin, 2005). There is a role of materialism in developing a demand for luxury goods among youth (sun, 2016). Research suggests that there is a direct relationship between materialistic society and gaining satisfaction in life. There is a relationship between materialism, lack of empathy and materialism. Buying more goods is self-destructive because it leads to depression (monbit, 2013).

Youth who are materialistic respond to the media advertisement and media celebrities positively (Kwan, 2013).Research suggests that there is a relationship between self and materialism among youth. Youth who have independent self-show positive respond to materialism (Gil1, 2016).According to research, level of materialism help us to explain the consumer behavior of youth. According to Amy (2013) investigated that today teens are more materialistic and less interested in working.

Kasser (2014) suggests that consumption of materialistic goods leads to self-satisfaction in life. Parents and peer transfer their attitude of consumption and using materialistic things to their children (Chaplin, 2010). Ruters (2007) suggests that $71 \%$ of teens are more materialistic and they became happy by spending money on themselves. The factors that are contributing to raising materialism among youth are media exposure, shopping centers, magazines, movies and music videos (Kwaku, 2010). According to Chaplin (2007), there is an effect of materialism among children and adolescents. 
Research suggests that there is a direct relationship between materialism and stress. Materialistic goods seem a source of happiness, but it is also related to stress (Brouskeli, 2014).According to Maslow's hierarchy of needs, the material world is more necessary than emotions. We can't reach to self-actualization when we are not satisfied with material goods (maslow, 2013). Meenakish (2011) investigated the relationship between materialism and fashion clothes among Indian female. The findings of this research show that young women take more interest in fashion than young males.

A research investigated the relationship between individual's materialistic concept and personal well-being. There is a positive link between materialism and lower well-being, and this wellbeing can directly cause the high-risk factors for health (Dittmar, 2014). High materialist spent more money on necessity items than low materialist (Brown, 2015). According to Richin (2004), there is an effect of materialism on emotional well-being and life satisfaction. A term is known as "model materialism" also studied in research that if parents are materialistic than their kids also be materialistic (Mian, 2009).

The findings of research suggest that materialistic youth like to shop more and save less. Youth who are materialistic show low academic performance (Goldberg, 2003). There is a great role of materialistic society where parent is distant from their children and media exposure of developing materialism among youth. It was also revealed that $69 \%$ of youth have their computer and $73 \%$ of teens use social networks (Gang, 2014).

Alumnder (2007) investigated the relationship between food and depression. It was revealed that by consuming more fast food, there is a higher risk of developing depression among youth. Research suggests the relationship of existing materialism conceptualization and measures shortcomings (Srikant, 2013). There is a positive relationship between materialism and purchase intention toward luxury goods (kamal, 2013).

\section{Rationalization}

Today, the materialistic trend is increasing so much in youth that they are living a robotic life and tried to be more competitive with each other. They spend more time on social media rather than their family and become more status conscious. Their purpose of life is to live a luxurious 
life and become a part of our elite of society that is why we choose this topic so that we can understand the factors which are the cause of enhancing this evil trend.

\section{Objectives}

The objective of our study is to find out the factors and to change them by altering the trend that is increasing materialism because they are the source of destruction which is reducing the emotions in youth and developing negative attitudes. Pakistan is the under develop country, and it is the need of our country to increase the level of education and focus on skills development, but the misuse of social media by our youth is doing an extremely different thing. People are not constructive they become more destructive because of inferiority complex and we should do something to change this type of thought pattern.

\section{Research question}

1. Is there any Materialistic element found in events and what do you think is the reason behind it?

2. Do you think materialism is creating any conflicts among parents and their children?

3. Do you think there is any effect of materialism on our society?

4. What do you think about social media and increase materialism among youth?

5. Do you think there is any role of brand in increasing self-esteem?

\section{METHOD}

The purpose of this qualitative study was to explore and describe the obsession of our youth towards materialistic things. We prefer qualitative research rather than quantitative because it will deeply explore the vision of an individual. There are different researches done on the study in West, and we wanted to explore it in our country. Therefore, qualitative methods are highly suitable for it (Packer-Muti, 2009). 


\section{Problem statement}

The problem statement is based on the notion that materialistic trend is increasing among youth. That is why we try to explore this belief by doing the research based on different questions that would help us to explore the reasons behind it.

\section{Research design}

The research design is based on a qualitative study in which interpretive phenomenological approach was used which rely on semi-structured interviews. These type of interviews are used because they give us a direction that how to explore or find out some relevant answers of your study. Semi-structured means that you can modify the research questions by asking some different sort of questions according to the characteristics of your participants.

\section{Sample}

The sample of this research included 25 people, age group 18-25 years obtained from students that are enrolled in universities of Lahore. Out of these 25 individuals, 13 were male, and the rest of them (12) were females. The collected data from both private and government institutes so that it would be more helpful to identify the factors behind this thought pattern.

\section{Measure or Tools of Inquiry}

To build a good relationship between the interviewee and interviewer, the Interviews began with simplest background questions like what they think about the factors that could be the source of a better lifestyle. The purpose behind starting with the simplest repo building question is to make the participant feel more comfortable as well as assist in gathering demographic information. A demographic form was introduced after the complete introduction to the topic. The researcher described to respondents about the purpose of the study and where it was going to be used. It was completely assured to them that their identity would be kept confidential. All conversation regarding the interviewee's work, life, and interest in the study was conducted. The different type of questions was asked of the participants that would help to identify the reason behind it like questions related to their lifestyle and the change that take place due to social media. 
Beside this, questions related to the expenditure of money on events and the conflict of ideas between parents and children were asked from them. These were the main tools that help to identify new themes and develop a structural model based on all those dimensions which could enhance materialism.

\section{Procedure}

When the study is going to proceed the first thing was to interact with the participants and for that purpose Face-to-face interviews were chosen that take place under natural setting. All interviews were audio-taped and the purpose behind recording is not to miss any single information that was given by the participants. Eight interviews took place in the cafeteria of the university of Comsats (Lahore Campus); eight interviews were conducted on the ground of Punjab University; two interviews occurred in an interviewee's place; and seven Interviews took place at various places. Before the interview started, each and every issue related to any query was discussed. The recording was obtained after the permission of participants who are going, beginning with, the interview.

These were the response of some of the basic questions that were asked by the researcher to the participants during the process of taking interviews from the participants.

\section{Basic things that are required for living a better life}

"There are different things that are necessary for living a better life but first of all, your surrounding social matters a lot if you spend more time with people around you. It will be healthier for your mind, which enhances the positivity in you, and beside this, honesty matters a lot if you are honest in your relationships. You will find inner satisfaction and your life become better".

2. Things that is necessary for building a new relationship.

"Trust and respect are the two main factors on which every relation should be based, and if there is no respect in a relation, then it becomes worthless. However, today people give more preference to the appearance rather than nature of a person". (R2). 
3. Are there any effects of materialism on youth?

"People are becoming more materialistic because they are brand conscious and always try to look more attractive towards other by buying expensive things like mobiles, cars, clothes, etc." (R3).

4. Is there any Materialistic element found in events and what the reasons behind it are. "The priority of people changes from relationship to status consciousness. People try to satisfy themselves by following the brands and by hiding their inner complexes. People spend more money on such events just to be a part of society". (R4).

5. Importance of spending time with family

"Family should be the priority because they are our emotional and social support, but due to the increased use of social websites people are far from their family."(R5).

6. Parent-child conflict due to materialism

"Yes, materialism has increased the thought conflict between parents and children. Because when priorities have changed than thoughts change then angles of thoughts change and at the end, relationships change because it all depends on priorities". (R 6).

7. Steps to stop people from moving towards materialism "Every person has his life. Then just guide them and teach them Islamic teachings and tell that these materialistic things give you nothing it's only a race, and at the end, we have to go to qabr". (R 7).

\section{Priorities for shopping}

"I consider my budget for shopping. If I like thing that is of my use then I will buy it on high price".

(R 8). 
9. Importance of belonging to a rich family

"The need of human never fulfilled. Human is greedy by nature. Life satisfaction cannot be bought from money. So, it is not necessary".(R 9).

10. Factors of lost purpose of life

"Purpose of life has lost due to materialism. A human can't understand the relations. It has become a phenomenon that if we don't have branded item, then people will not accept us due to which relationships effect a lot".(R 10).

11. Factors affecting the home building

"According to me, a home should be according to need. If a home is big just for show off, then it is wrong".

(R 11).

12. Role of materialism for ideal life

"According to me life should be spent in limits. Satisfaction has a relation with soul and soul has a relation with Allah but we see our upper class, and we try to reach that position like mobile phones etc. that help us in contacting with other people in our leisure time" (R 12).

\section{Places for food preferences}

"I like Mc Donald's and KFC and MM ALAM Road restaurants." (R 13).

These were the different questions that were asked in the study so that different themes could derive from it.

\section{Data Analysis}

In the process of analyzing, all the data is transcribed by the researcher and then from that transcribed data themes and categories were described, so it was decided that the themes and categories will be explained in tabular form. 
In the table, the analyzed data divided into domains, core ideas and categories. In domain section it was tried to explain the main content of the question, then the core ideas by replies of the research participants and at last, categories of answers of participants were explained.(please see Table 1 for results).

Table 1

Domain, Core Ideas, And Categories

Domain Core Idea Category

I. Source of life satisfaction R Q:1

A Materialistic Things

B Relationships

II. Sources of materialism R Q:2

III. Sources of social destruction R Q:3

A Parenting

B Social media

A Self-centered
B Jealousy

C Materialistic relations

A Class conflict

IV. Factors of materialistic events R Q:4 V. Importance of spending
time with family $R$ Q:5
A Lesson communication gap

1 Luxuries

2 Education

1 Honesty

2 Basic necessities

3 Respect

4 Faith/religion

1 Low moral or ethical

2 values

lust

1 Show off

2 Change of vision

3 Brand consciousness

4 Status conscious

5 Lack of emotions

1 No justice

1 Disturbed life

1 Frustration

2 Depression

3 Trends of late marriages

1 Increase of complexes

2 Social image

3 Social pressure

4 Dowry

1 Trust development

2 Sharing of ideas and thoughts 


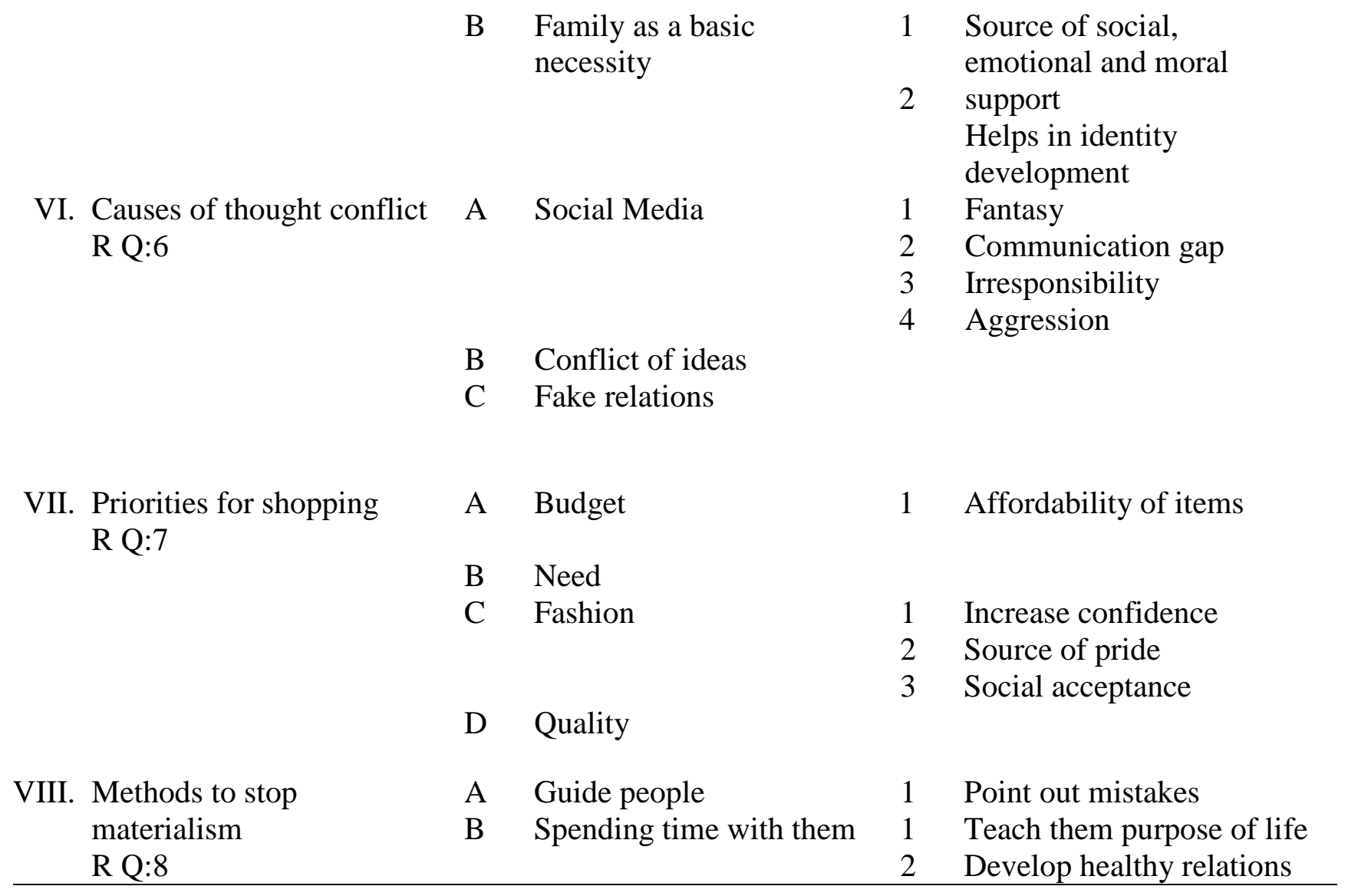

\section{Ethical consideration}

Research ethics are very necessary for completion of research. Following ethics were considered for completion of research. It was tried that research participants were not subjected to any harm. A specific consent was taken before taking interview from them. It was also ensured about the confidentiality of participants. Participants were not forced for giving answers during the interview. Deception was avoided, and it was ensured about the dignity and respect of participants and their point of views. In fact, all the research was done with full honesty, and it was also tried to avoid biases.

\section{RESULT}

This qualitative study addressed the following FIVE major research questions, and many of the probing questions were asked from the participants to get the main themes. The supervisor 
reviewed all the domains and core ideas and listened to the Researcher's description of those initial categories. Then the supervisor shows all different types of label and charts that could be used to explain better the meaning of domains, core ideas, and categories derived by the research team. The researcher tries to explain the main research questions with the help of pie charts and make the result.

- It was asked from the participants that which thing brought peace to life and made our lives better. It was derived from

the research that $36 \%$ people depend on materialistic things for living a satisfied life and the rest $64 \%$ who believe in relationship dependency also rely on materialistic resources for the betterment of relationships.
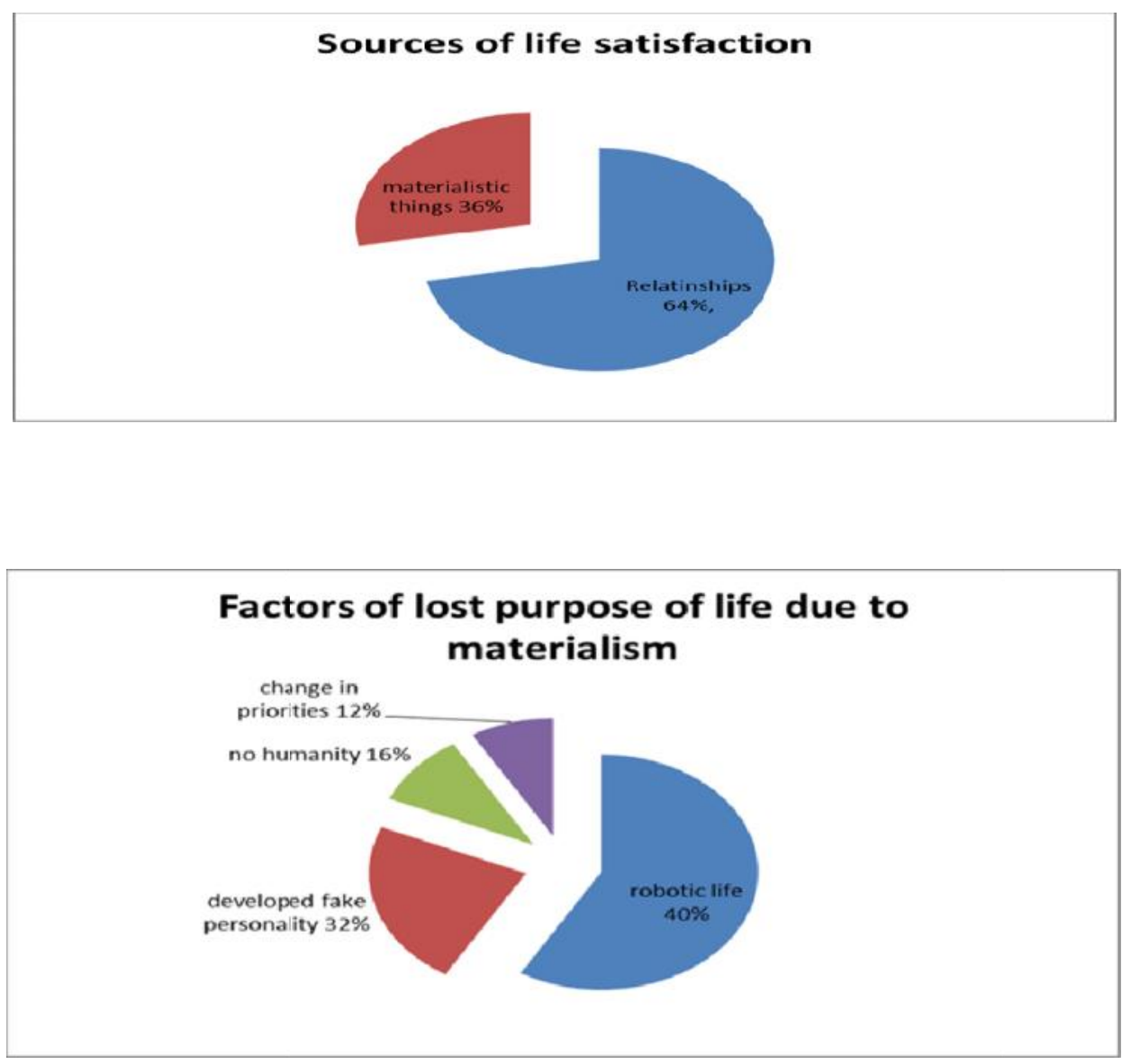
$40 \%$ of the people said life is being more robotic because our priorities have been changed, and $32 \%$ said that it is because of the development of fake personalities and the elimination of originality which make us less empathetic and $16 \%$ believed that duey to having no concern for humanity each and every person is dissatisfied with their life because the inner satisfaction is not there.

When was it asked the participants that do you think there is any effect of materialism on our society?

- What do you think about social media and increase materialism among youth?

It was a scene that the source of materialism is the social media which is developing status consciousness among people which enhances negativity within societies. People have more lust for money, and they heavily rely on it. There is also a role of parenting because if parents have this deprivation of money in them, then their children will also have it because of lack of emotional bonding within relations.

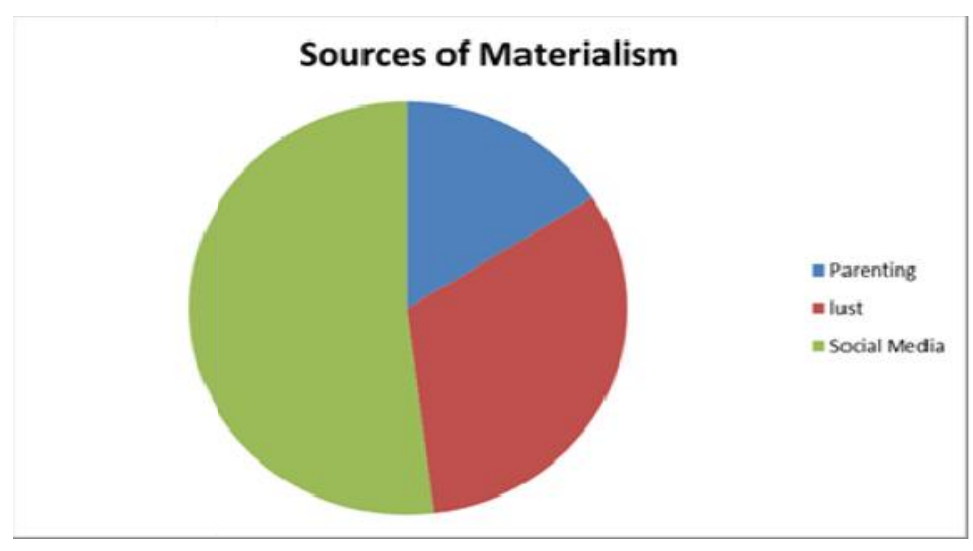




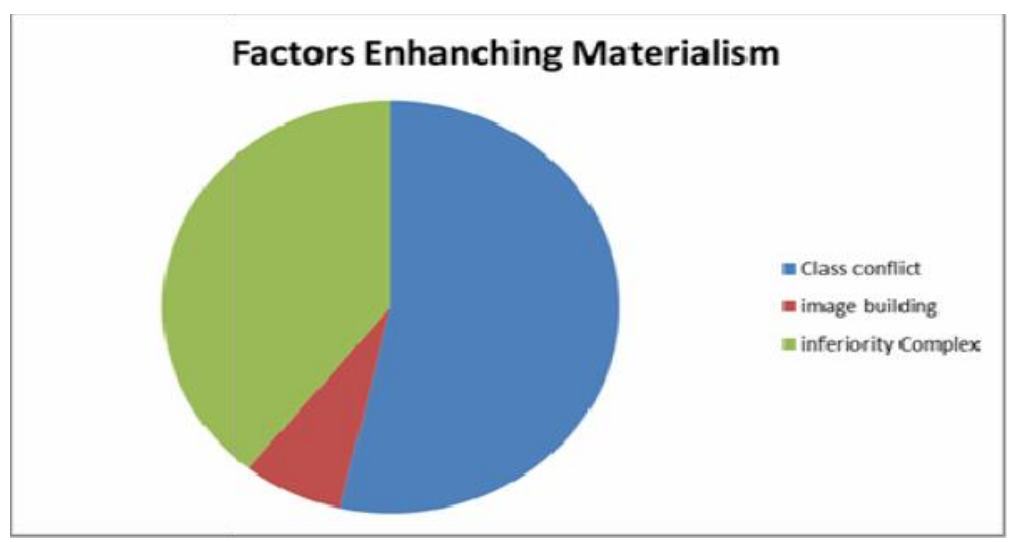

So it was found out that materialism is playing a negative role, and it is the source of destruction than that if construction. Because $40 \%$ of respondents believed that they are living a life that is the requirement of society and that is why $32 \%$ said that it causes the destruction of happiness and ruin the originality of relations.

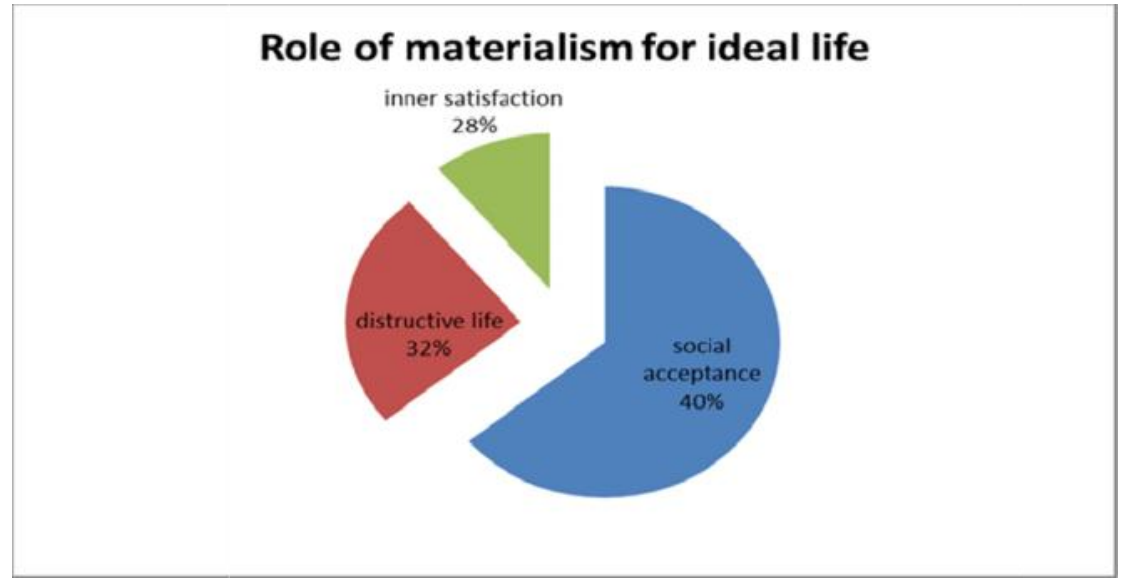

When was it asked of the participants that what do you think about the role of brand in increasing self-esteem? Most of them were against it and told that brand is not increasing any self-esteem however it created people more self-centered and 36 said that it developed a sense of brand consciousness among people regarding their outer looks. 


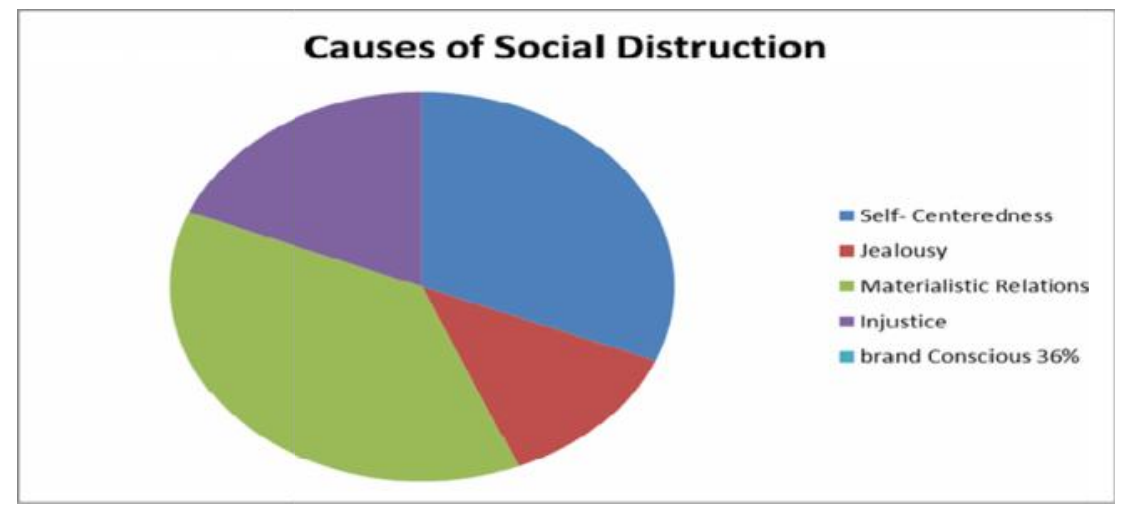

Especially when it was asked that do you think materialism is creating any conflicts among parents and their children? Most of the participants replied yes to it because they believe that parents are considered to be least important, and children give more attention to other things like spending more time on the internet and living a life under imaginary thoughts of being the top of this world.

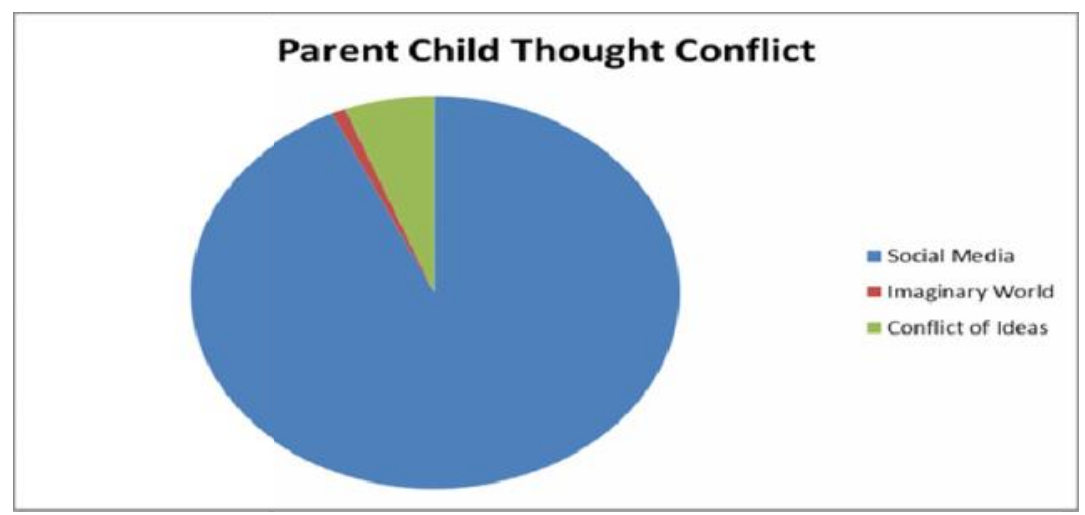

Some respond that $32 \%$ who is living a luxurious life by belonging to wealthy family are more materialistic and have more conflicts with their parents. 


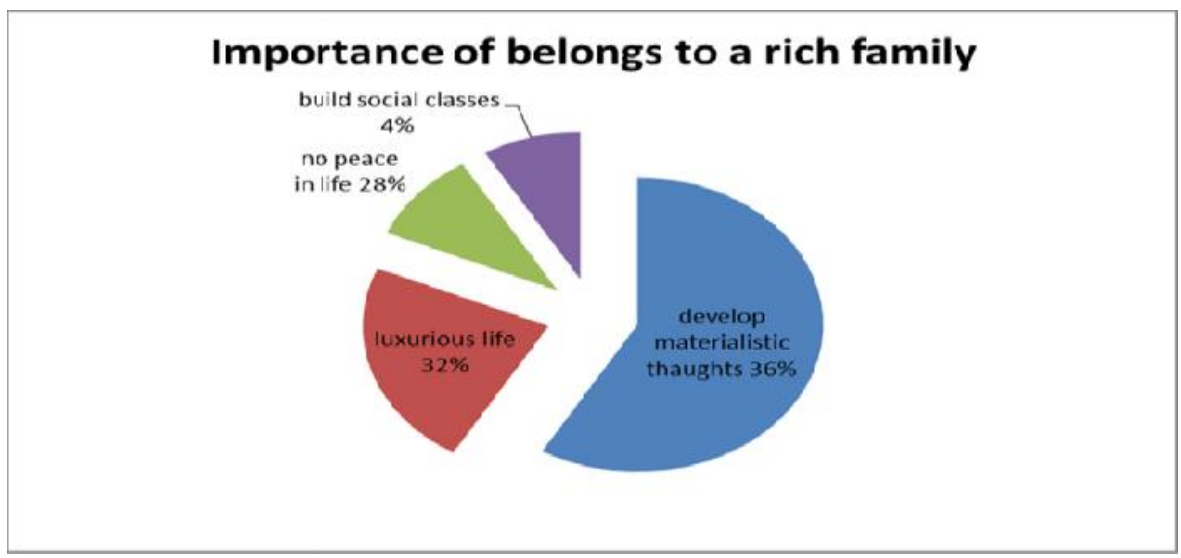

\section{Discussion}

The majority of participants explained that materialism developed due to change in societal trends and increase trends of social media. Especially youth is more motivated towards materialistic things. One of the participants replied that:

"People are becoming more materialistic because they are brand conscious and always try to look more attractive towards other by buying expensive things like mobiles, cars, clothes, etc."

The increasing materialistic trends in society are due to change in priorities. Today, youth develop relationships by materialistic things than that of loyalty. One participant mentioned that:

"The priority of people changes from relationship to status consciousness. People try to satisfy themselves by following the brands and by hiding their inner complexes. People spend more money on such events just to be a part of society".

One of the studies also explained the same phenomenon that Two factors that enhance materialism were when people got any signal from friends, peers, parents and family members and the second factor comes when people feel insecure because of economic fears (Kasser, 2014). One of our participants also explained the materialism during the interview. He stated that: 
"There are different things that are necessary for living a better life but first of all, your surrounding social matters a lot if you spend more time with people around you. it will be healthier for your mind which enhance the positivity in you, and beside this, honesty matters a lot if you are honest in your relationships you will find inner satisfaction and your life become better".

The discussions mentioned above will help you to understand the today's trends of materialism among youth and also help you to understand the contributory factors of materialism among youth.

\section{Limitations and strengths}

The strength of this research is that it will explain you in detail the materialism among youth qualitatively. This research will guide you to understand the materialistic trends that are increasing in today's youth. It will also guide you the cause and contributory factors of materialism among youth. The method of data collection was also very effective that is semistructured interview. It helps the participants to share their point of views and lifestyle. We tried our best to make the environment comfortable for participants so that they can share their life experiences easily.

This research will also help you to understand the materialism regarding psychology that will provide you platform for future studies. This study covers almost equal ratio of male and female participants of almost same age, so it will help you to understand the why today's youth moving towards materialism

The limitation of this research is that it cannot be generalized for the whole population. The findings of this study are limited because it covers a small sample of the entire population. Another limitation of this study is the interviewer's biases and participant's knowledge. Although, we tried our best to avoid the biases during data collection and analysis due to different personality type of researcher it cannot be reduced completely. All these limitations should be considered in future research. 


\section{CONCLUSION}

This study attempted to explain the materialistic trends and record the life experiences of 25 participants of which 13 are male, and 12 are female. This study is based on life experiences of participants, and it is due to the patience and courage of participants who share their experiences and helped us a lot to complete this qualitative research.

The result of this study explained that materialistic trends are increasing among youth nowadays. Because thought patterns of youth and societal demands have changed totally. Life satisfaction can only get after having materialistic things. It is the research that hopes that more you consider the thoughts of society the more you get involve in materialistic trends.

\section{REFERENCES}

Achenreiner, G. B. (1997). Materialistic values and susceptibility to influence in children. Advances in Consumer Research, 24, 82-88.

Achenreiner, G. B., \& Roedder John, D. (2003). The Meaning of Brand Names to Children: A Developmental Investigation. Journal of Consumer Psychology, 13(3), 205-219.

Rindfleisch, A., Burroughs, J. E., \& Denton, F. (1997). Family structure, materialism, and compulsive consumption. Journal of Consumer Research, 23(4), 312-325.

Belk, R. (1988). Possessions as the extended Self. Journal of Consumer Research , 15, 139-168.

Boven, L. v. (2005). Experientialism, materialism, and the persuit of happiness. Review of journal Psychology, 9 (2), 132-142.

Brouskeli, V. (2014). Materialism, stress and health behaviors among future educators. Journal of Education and Training Studies, 2(2), 145-150.

Chaplin, L. N., \& John, D. R. (2007). Growing up in a material world: Age differences in materialism in children and adolescents. Journal of Consumer Research, 34(4), 480-493.

DOI: $10.1086 / 518546$ 
Chaplin, L. N. (2010). Interpersonal influence on adolescent materialism: A new look at the role of parents and peers. Journal of Consumer Psychology , 20, 176-184.

Chaplin, L. N., \& John, D. R. (2005). The development of self-brand connections in children and adolescents. Journal of Consumer Research, 32(1), 119-129.

Chee, b. (2013). Today teens, more materialistic and less willing to work. SDSU .

Diener, E., \& Fujita, F. (1995). Resources, personal strivings, and subjective well-being: A nomothetic and idiographic approach. Journal of Personality and Social Psychology, 68 (5), 926-935.

Dittmar, H., Bond, R., Hurst, M., \& Kasser, T. (2014). The relationship between materialism and personal well-being. Journal of Personality and Social Psychology, 107(5):879-924.

Gang, B. (2014). Youth culture and coming of age. Understanding Materialism Among Youth . Retrieved December, 15, 2016 from youthcultureandcomingofage.blogspot.com/2014/

Gil, L. A., Leckie' C., \& Johnson, L. (2016). The impact of self on materialism among teenagers. Journal of Consumer Behavior, 15(3), 281-288.

Goldberg, M. E. (2003). Understanding materialism among youth. Journal of Consumer Psychology, 278-288.

Hoyer, W. D. (1990). Effects of brand awareness on choice for a common,report-purchase product. Journal of Consumer Research , 17 (2), 141-148.

John, D. R. (2003). The meaning of brand names to children: A developmental investigation. Journal of Consumer Psychology, 13 (3), 205-219.

Kamal, S., Shu-Chuan Chu., \& Pedram, M. (2013). Materialism, attitudes, and social media usage and their impact on purchase intention of luxury fashion goods among American and Arab young generations. Journal of Interractive Advertising, 13(1), 27-40.

Kwan, C. W. (2013). The relationship between advertising and the level of. Discovery - SS Student E-Journal ,3, 68-89. 
Marmot, M. (2001, may). Psychosocial and material pathways in the relation between income and health. Education And Debate . Education And Debate, 322, 1233-1241.

Maslow, A. (2013). Maslow and materialism. Retrived November, 12, 2016 from https://bonesofculture.wordpress.com/2013/08/25/maslow-and-materialism/

McLeod, M. R. (2005). Adolescents brand consciousness and product placements: Awareness, liking and perceived effects on self and others. International Journal of Consumer Studies , 29 (6), 515-528.

Monbit, G. (2013). Materialism: a system that eats us from the inside out. The Guardian.

Packer-Muti, B. (2009). Basics of qualitative research: Techniques and procedures for developing grounded theory. A Review of Corbin and Strauss, 2, 140-143.

Rayan, R. M. (2004, January). Materialistic values: Their causes and consequences.

Richins, M. L. (1994). Special possessions and the expression of material values. Journal of Consumer Research , 21 (3), 522-533.

Rosenberg, M. (1988). Society and the adolescent self-image. Determinants of Self-Esteem. Princeton: Princeton University Press

van Schalkwyk, G. J., Tran, E., \& Chang, K. (2006), The Impact of Macao's Gaming Industry on Family Life.China Perspectives [Online], 64 , retrieved December 15, 2016 from http://chinaperspectives.revues.org/603

Sun, g. (2016). The Intermediate Linkage Between Materialismand Luxury Consumption:

Evidence from the Emerging market of China. Social Indicators Research · February 2016. Retrieved from https://www.researchgate.net/publication/295686381.

Syrjals, H. (2002). Social needs in Finnish young adults' mundane consumption. Young Consumers , 16 (3), 301-315.

Taylor, S. (2012). Madness of materialism. Psychology Today . Retrieved june, 13, 2016 from https://www.psychologytoday.com/blog/out-the-darkness/201203/the-madnessmaterialism 
Telpade, M. (n.d.). Materialism and life satisfaction among Hispanic immigrant males. Journal of International Buisness and cultural Studies, 5, 1-8.

Zhang, Y. (2015). Peer rejection and adolescent materialism: Implicit self-esteem as a mediator. Journal of Experimental Social Psychology, 58, 48-55. 